\title{
Spectrum Efficiency of WiMAX Networks in the Presence of Interference with Diversity Combining
}

\author{
S. Thai Subha \\ Department of Electrical \& Electronics Engineering \\ SRM University, Kattankulathur, \\ Kancheepuram Dt. - 603203, Tamilnadu, India.
}

\author{
Vidhyacharan Bhaskar \\ Department of Electronics \& Communication \\ Engineering, \\ SRM University, Kattankulathur, \\ Kancheepuram Dt. - 603203, Tamilnadu, India.
}

\begin{abstract}
WiMAX (Worldwide Interoperability for Microwave Access) is a promising technology which can offer high speed voice, video and data services upto the requirements at the customer's end. The objectives of this paper is to evaluate the Performance evaluation of a WiMAX system under various diversity schemes (Selection combining, Maximal ratio combining and Equal gain combining), employing different adaptive transmission policies, such as Optimal power and rate adaptation policy, Optimal rate adaptation with constant transmit power policy, Channel inversion with fixed rate policy, and Truncated channel inversion policy, subjected to co-channel interference and adjacent channel interference. WiMAX system incorporates OFDM with 256 sub-carriers with QPSK modulation as the transmission scheme. Simulated results of the estimated spectrum efficiency show that the implementation of Optimal power and rate adaptation policy under Selection combining is highly effective to combat cochannel interference and adjacent channel interference in the WiMAX communication system.
\end{abstract}

\section{Keywords}

Co-channel interference; Adjacent channel interference; Optimal power and rate adaptation policy; Optimal rate adaptation with constant transmit power policy; Channel inversion with fixed rate policy; Truncated channel inversion with fixed rate policy.

\section{INTRODUCTION}

WiMAX offers wireless access as an alternative to fixed access, e.g. Digital Subscriber Line (DSL) at high data rate Internet services, and extends broadband services with mobility to areas where currently no fixed broadband access is feasible due to excessive costs on the last mile. The demand for broadband mobile services continues to grow. Conventional high-speed broadband solutions are based on wired-access technologies such as DSL. This type of solution is difficult to deploy in remote rural areas; further it lacks support for terminal mobility. Mobile Broadband Wireless Access (MBWA) offers a flexible and cost-effective solution to these problems [1].

IEEE WiMAX/802.16 is a promising technology for broadband Wireless Metropolitan Area Networks (WMANs), as it can provide high throughput over long distances and can support different Qualities of Service (QoS). WiMAX/802.16 technology ensures broadband access to the last mile. It provides a wireless backhaul network that enables high speed Internet access to residential, small, and medium business customers, as well as Internet access for Wi-Fi hot spots and cellular base stations [2]. It supports both Point-to-MultiPoint (P2MP) and multipoint-to-multipoint (mesh) modes. WiMAX will substitute other broadband technologies competing in the same segment and will become an excellent solution for the deployment of well-known last mile infrastructures in places where it is very difficult to obtain with other technologies, such as cable or DSL, and where the costs of deployment and maintenance of such technologies would not be profitable. In this way, WiMAX will connect rural areas in developing countries as well as underserved metropolitan areas. It can even be used to deliver backhaul for carrier structures, enterprise campus, and Wi-Fi hot-spots. WiMAX offers a good solution for these challenges because it provides a costeffective, rapidly deployable solution [3].

Additionally, WiMAX will represent a serious competitor to 3G (Third Generation) cellular systems as high speed mobile data applications will be achieved with 802.16 e specification. The IEEE 802.16-2004 standard specifies Orthogonal Frequency Division Multiplexing (OFDM) as the transmission method for Non-Line of Sight (NLOS) connections. OFDM signal is made up of many orthogonal carriers, and each individual carrier is digitally modulated with a low symbol rate. This method has distinct advantages in multipath propagation, because in comparison with the single carrier method at the same transmission rate, more time is needed to transmit a symbol. BPSK, QPSK, 16-QAM, and 64-QAM modulation modes are used and modulation is adapted to the specific transmission requirements. Transmission rates of upto $75 \mathrm{Mbps}$ are possible [4]. IEEE 802.16 aims to extend wireless broadband access upto kilometers in order to facilitate both Point-to-Point (P2P) and P2MP connections [5].

In this paper, simulation results of spectrum efficiency in a WiMAX network employing OFDM 256 subcarriers is obtained, and compared with the spectrum efficiency expressions derived in our earlier papers.

\section{SYSTEM MODEL}

The PHYsical (PHY) layer of WiMAX is based on OFDM, a scheme that offers good resistance to multipath and allows WiMAX to operate in NLOS conditions. Fixed WiMAX is based on IEEE 802.16-2004, and uses 256 Fast Fourier transform (FFT)-based OFDM physical layer. For this version, the FFT size is fixed at 256, of which 192 subcarriers are used to carry data, 8 used as pilot carriers for channel estimation and synchronization purposes and the rest as guard band subcarriers. 


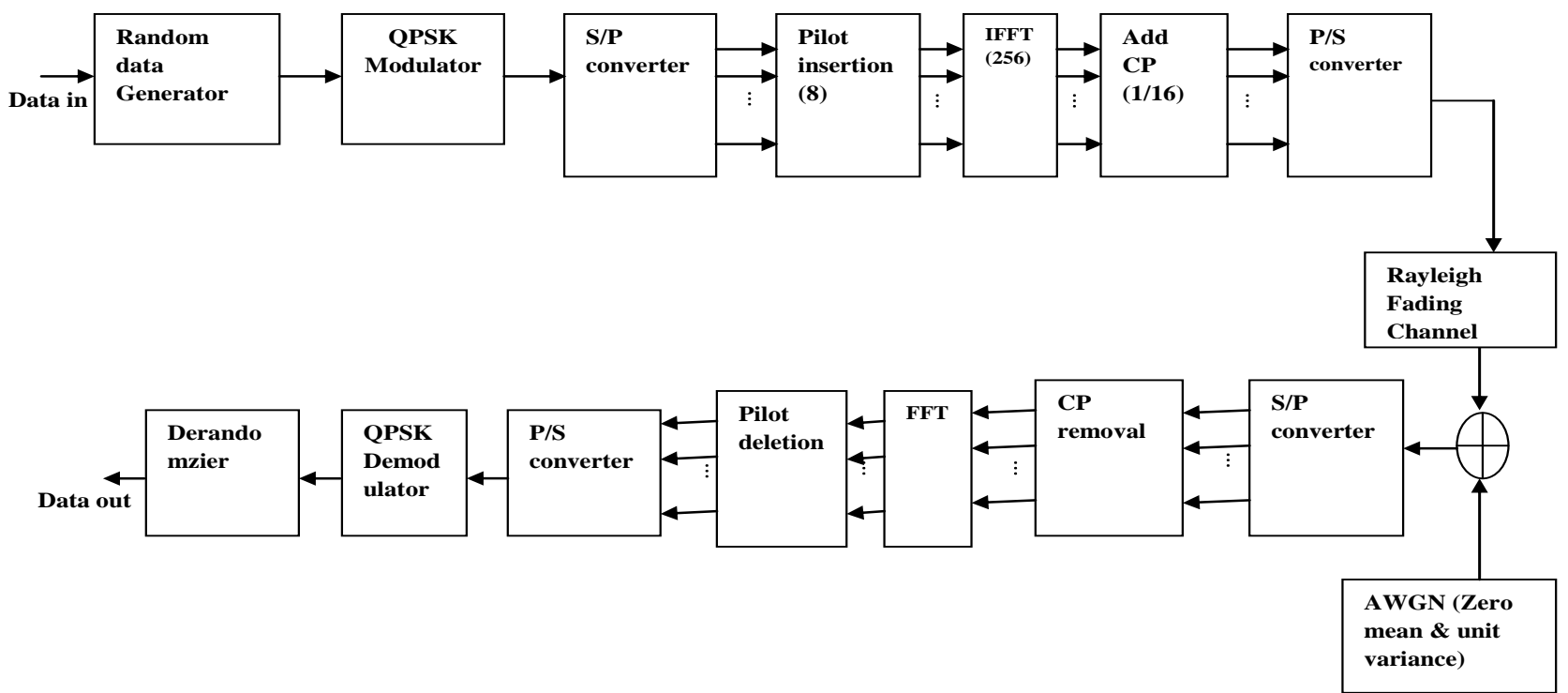

Fig. 1: WiMAX OFDM physical layer.

Fig. 1 shows a Fixed WiMAX OFDM PHY layer. At the transmitter, the incoming data stream is first encoded using a randomizer and mapped onto QPSK symbols. Using a serialto-parallel converter, a serial bit stream is converted into parallel bit streams. Pilot symbols are then inserted that can be used to perform frequency offset compensation and channel estimation at the receiver. Inverse Fast Fourier Transform (IFFT) is then performed with 256 points to produce a time domain signal. Cyclic Prefix (CP) of 16 samples are inserted to combat the effects of Inter Symbol Interference (ISI) at the beginning of each symbol, and removed at the receiver before the demodulator. Again, after using a parallel-to-serial converter, the symbols are transmitted through the channel. The received signal is the sum of linear convolution of the transmitted signal with the discrete channel impulse response, and an Additive White Gaussian Noise (AWGN) channel with zero mean and unit variance is added. It is assumed that channel fading is Rayleigh. The PHY layer at the receiving side then performs the reverse operations, such as removal of $\mathrm{CP}$, pilot symbols, and FFT is performed to obtain the data symbol.

\section{SNIR OF CCI AND ACI}

The generalized expression for Signal to Noise plus Cochannel Interference ratio is given by [6]

$$
\frac{\mathrm{S}}{(\mathrm{N}+\mathrm{I})}=\left[\left(\frac{\mu^{2} \mathrm{E}_{\mathrm{b}}}{\mathrm{N}_{0}}\right)^{-1}+\left(\frac{\mathrm{S}}{\mathrm{I}}\right)_{\mathrm{CCI}}^{-1}\right]^{-1} \text {, }
$$

where $\left(\frac{\mu^{2} E_{b}}{N_{0}}\right)$ represents SNR considering AWGN and

Rayleigh fading, $\mu$ represents the Rayleigh faded random variable, and since signals from other cells' base stations arrive at the reference user asynchronously even when the system is designed to be inter-cell synchronous, multiuser interference due to transmissions from base stations other than the reference base station is approximated as

$$
\left(\frac{\mathrm{S}}{\mathrm{I}}\right)_{\mathrm{CCI}}^{-1}=\sum_{\mathrm{i}=1}^{\mathrm{i}_{0}} \frac{2}{3 \mathrm{~N}}\left(\sum_{\mathrm{k}=1}^{\mathrm{k}_{\mathrm{i}}} \frac{\mathrm{P}_{\mathrm{ik}}}{\mathrm{P}_{0}}\right)
$$

Here, $\mathrm{N}=\mathrm{W} / \mathrm{R}$ is the system processing gain (Total channel bandwidth/Data rate of one user), $\mathrm{k}_{\mathrm{i}}$ represents the number of users within the $\mathrm{i}^{\text {th }}$ co-channel cell, $\mathrm{P}_{\mathrm{ik}}$ represents the average transmit power from the $i^{\text {th }}$ co-channel's base station to the $\mathrm{k}^{\text {th }}$ user in that co-channel cell as received by the reference user in the reference cell. In practice, only the first-tier co-channel cells (cells adjacent to the reference cell) significantly affect $(\mathrm{S} / \mathrm{I})_{\mathrm{CCI}}$. The effect on $(\mathrm{S} / \mathrm{I})_{\mathrm{CCI}}$ of the second-tier co-channel cells (cells adjacent to the first-tier cochannel cells) can be included in the overall SNR expression, but due to its relatively negligible effect of second-tier cochannel cells as well as higher than that will be omitted.

The generalized expression for signal to noise plus adjacent channel interference ratio is given by [6]

$$
\frac{\mathrm{S}}{(\mathrm{N}+\mathrm{I})}=\left[\left(\frac{\mu^{2} \mathrm{E}_{\mathrm{b}}}{\mathrm{N}_{0}}\right)^{-1}+\left(\frac{\mathrm{S}}{\mathrm{I}}\right)_{\mathrm{ACI}}^{-1}\right]^{-1}
$$

where $\left(\frac{\mathrm{S}}{\mathrm{I}}\right)_{\mathrm{ACI}}^{-1}=\frac{2 \lambda}{3 \mathrm{NG}^{2}} \sum_{\mathrm{k}=1}^{\mathrm{k}_{0}} \frac{\mathrm{P}_{\mathrm{k}}}{\mathrm{P}_{0}}$

Here, $G$ represents power gain of the IF filter for the desired signal relative to the adjacent channel, $\lambda$ represents correlation of the received amplitudes of two signals transmitted from the same base station and received at the same mobile as a function of their frequency separation, $\mathrm{k}_{0}$ represents the number of users in the reference cell, $\mathrm{P}_{\mathrm{k}}$ represents the average transmitted power from the reference base station to the $\mathrm{k}^{\text {th }}$ user in the reference cell as received by the reference user in the reference cell. 


\section{SPECTRUM EFFICIENCY OF VARIOUS DIVERSITY SCHEMES}

\subsection{Diversity Schemes}

In a high-capacity mobile radio system, the reduction of CCI can be the most important advantage of diversity. The SIR is improved with the number of diversity branches. When Selection Combining (SC) is subjected to CCI, selection could be one of several decision algorithms: First, the total power algorithm selects the branch with the largest total intermediate frequency (IF) received power and is probably the easiest to implement in practice. Secondly, in other decision algorithm, the signals and interferers could be identified by different pilots, transmitted along with each of them. The combiner then selects the branch with the largest desired signal power (desired-signal-power algorithm). When subjected to CCI, the performance of Maximal-Ratio Combining (MRC) and Equal Gain Combining (EGC) depends on the means with which the branch gains are determined [7].

\subsection{Adaptation Policies}

Assuming that channel is estimated at the receiver, adaptive techniques require a feedback path between the transmitter and the receiver. Four adaptation policies are considered: Optimal Power and Rate Adaptation policy (OPRA), Optimal Rate Adaptation (ORA) with constant transmit power policy, Channel Inversion with Fixed Rate (CIFR) policy, and Truncated channel Inversion with Fixed Rate (TIFR) policy. The OPRA policy uses variable rate and power transmission whereas the ORA policy uses receiver side information alone in which code design makes use of channel correlation statistics. The CIFR and TIFR polices adapts the transmission power, but keeps the transmission rate constant, i.e., it inverts the channel fading.

\subsection{Expressions for Spectrum Efficiency when subjected to $\mathrm{CCI}$}

The closed form solution for the PDF of output IF SNIR is given by Equation (5.4-83) on page 364 of [7] as

$\mathrm{p}_{\gamma}^{\mathrm{SC}, \mathrm{CCI}}(\gamma)=\mathrm{M} \Gamma \sum_{\mathrm{k}=0}^{\mathrm{M}-1}\left(\begin{array}{c}\mathrm{M}-1 \\ \mathrm{k}\end{array}\right)(-1)^{\mathrm{k}}[\gamma(\mathrm{k}+1)+\Gamma]^{-2}$,

where $\gamma$ represents the instantaneous selected branch SNIR, $\Gamma$ is the average SNIR, M denotes the number of diversity branches. Using this PDF, various analytical expressions for the parametric measures considered are derived for SC diversity under various adaptation policies when the system is subjected to CCI. Given an average transmit power constraint, the channel capacity of a fading channel with received SNR distribution and OPRA policy, $\langle\mathrm{C}\rangle_{\text {OPRA }}$ bits/s, is given as [8]

$$
\langle\mathrm{C}\rangle_{\mathrm{opra}}=\mathrm{B} \int_{\gamma_{0}}^{\infty} \log _{2}\left(\frac{\gamma}{\gamma_{0}}\right) \mathrm{p}(\gamma) \mathrm{d} \gamma
$$

where B $(\mathrm{Hz})$ is the channel bandwidth, and $\gamma_{0}$ is the cutoff level SNR below which data transmission is suspended. This cutoff must satisfy the following equation [8]

$$
\int_{\gamma_{0}}^{\infty}\left(\frac{1}{\gamma_{0}}-\frac{1}{\gamma}\right) \mathrm{p}(\gamma) \mathrm{d} \gamma=1
$$

The spectrum efficiency, $\frac{\langle\mathrm{C}\rangle_{\mathrm{OPRA}}^{\mathrm{SC}, \mathrm{CCI}}}{\mathrm{B}}[\mathrm{bps} / \mathrm{Hz}]$, for OPRA policy for SC diversity case under CCI is obtained as

$$
\frac{\langle\mathrm{C}\rangle_{\mathrm{OPRA}}^{\mathrm{SC}, \mathrm{CCI}}}{\mathrm{B}}=\frac{\mathrm{M} \Gamma}{\ln 2} \sum_{\mathrm{k}=0}^{\mathrm{M}-1}\left(\begin{array}{c}
\mathrm{M}-1 \\
\mathrm{k}
\end{array}\right)(-1)^{\mathrm{k}}\left[\frac{1}{\mathrm{k}+1} \ln \left(\frac{\gamma_{0}+\frac{\Gamma}{\mathrm{k}+1}}{\gamma_{0}}\right)\right] .
$$

Adapting the code rate to channel conditions with a constant transmit power, the channel capacity, $\langle\mathrm{C}\rangle_{\mathrm{ORA}}$, is given as [8]

$$
\langle\mathrm{C}\rangle_{\text {ora }}=\mathrm{B} \int_{0}^{\infty} \log _{2}(1+\gamma) \mathrm{p}(\gamma) \mathrm{d} \gamma
$$

The spectrum efficiency, $\frac{\langle\mathrm{C}\rangle_{\mathrm{ORA}}^{\mathrm{SC}, \mathrm{CCI}}}{\mathrm{B}}[\mathrm{bps} / \mathrm{Hz}]$, for ORA policy for the SC diversity case under CCI is obtained as

$$
\langle\mathrm{C}\rangle_{\text {ora }}^{\mathrm{SC}, \mathrm{CCI}}=\frac{\mathrm{M} \Gamma}{\ln 2} \sum_{\mathrm{k}=0}^{\mathrm{M}-1}\left(\begin{array}{c}
\mathrm{M}-1 \\
\mathrm{k}
\end{array}\right)(-1)^{\mathrm{k}}\left[\frac{\ln \frac{\mathrm{k}+1}{\Gamma}}{(\mathrm{k}+1)(\mathrm{k}+1-\Gamma)}\right] \cdot(10)
$$

The channel capacity with CIFR policy, $\langle\mathrm{C}\rangle_{\mathrm{CIFR}}$, is given by [8]

$$
\langle\mathrm{C}\rangle_{\mathrm{cifr}}=\mathrm{B} \log _{2}\left(1+\frac{1}{\int_{0}^{\infty} \frac{\mathrm{p}(\gamma)}{\gamma} \mathrm{d} \gamma}\right) \text {. }
$$

The spectrum efficiency, $\frac{\langle\mathrm{C}\rangle_{\mathrm{CIFR}}^{\mathrm{SC}, \mathrm{CCI}}}{\mathrm{B}}[\mathrm{bps} / \mathrm{Hz}]$, under $\mathrm{CIFR}$ $\begin{aligned} & \text { policy for } \\ & \text { obtained }\end{aligned}$
SC diversity under $\mathrm{CCI}$ is

$$
\left.\frac{\langle\mathrm{C}\rangle_{\mathrm{CIFR}}^{\mathrm{SC}, \mathrm{CCI}}}{\mathrm{B}}=\log _{2}\left[1+\frac{1}{\frac{\mathrm{M}}{\Gamma} \sum_{\mathrm{k}=0}^{\mathrm{M}-1}\left(\begin{array}{c}
\mathrm{M}-1 \\
\mathrm{k}
\end{array}\right)(-1)^{\mathrm{k}}\left[\ln \frac{1}{\mathrm{k}+1}-\left(\ln \frac{\gamma}{\gamma(\mathrm{k}+1)+\Gamma}+1\right)_{\gamma \rightarrow 0}\right.}\right]\right]
$$

The capacity with this TIFR policy, $\langle\mathrm{C}\rangle_{\mathrm{TIFR}}$, is given as [8]

$$
\begin{aligned}
& \langle C\rangle_{\text {tifr }}=B \log _{2}\left(1+\frac{1}{\int_{\gamma_{0}}^{\infty} \frac{\mathrm{p}(\gamma)}{\gamma} \mathrm{d} \gamma}\right)\left(1-\mathbf{P}_{\text {out }}\right), \\
& \text { where } \mathbf{P}_{\text {out }}=1-\int_{\gamma_{0}}^{\infty} \mathrm{p}(\gamma) \mathrm{d} \gamma
\end{aligned}
$$

The spectrum efficiency, $\frac{\langle\mathrm{C}\rangle_{\mathrm{TFR}}^{\mathrm{SC}, \mathrm{CCI}}}{\mathrm{B}}[\mathrm{bps} / \mathrm{Hz}]$, under TIFR policy for SC diversity under CCI is obtained as $\frac{\langle\mathrm{C}\rangle_{\mathrm{TIFR}}^{\mathrm{SC}, \mathrm{CCI}}}{\mathrm{B}}=\log _{2}\left[1+\frac{1}{\frac{\mathrm{M}}{\Gamma} \sum_{\mathrm{k}=0}^{\mathrm{M}-1}\left(\begin{array}{c}\mathrm{M}-1 \\ \mathrm{k}\end{array}\right)(-1)^{\mathrm{k}\left(\frac{-\Gamma}{(\mathrm{k}+1) \gamma_{0}+\Gamma}-\ln \frac{\gamma_{0}}{\gamma_{0}+\frac{\Gamma}{\mathrm{k}+1}}\right)}}\right]$

$$
\mathrm{x}\left(\sum_{\mathrm{k}=0}^{\mathrm{M}-1}\left(\begin{array}{c}
\mathrm{M}-1 \\
\mathrm{k}
\end{array}\right) \frac{\mathrm{M} \Gamma(-1)^{\mathrm{k}}}{(\mathrm{k}+1)^{2}\left(\gamma_{0}+\frac{\Gamma}{\mathrm{k}+1}\right.}\right)
$$


Analytical expressions for the parametric measures considered are derived in a similar manner as that of SC diversity for MRC and EGC diversity schemes under different adaptation policies. Table 1 shows the spectrum efficiency expressions
[8] for various diversity schemes such as SC, MRC and EGC under various adaptation policies considered when subjected to Co-Channel Interference (CCI).

Table I: Spectrum efficiency of various diversity schemes when subjected to CCI [9].

\begin{tabular}{|c|c|c|}
\hline $\begin{array}{l}\text { Diversity } \\
\text { schemes }\end{array}$ & $\begin{array}{l}\text { Adaptation } \\
\text { policies }\end{array}$ & Spectrum efficiency expressions \\
\hline \multirow{4}{*}{ SC } & OPRA & $\frac{\langle\mathrm{C}\rangle_{\mathrm{opra}}^{\mathrm{SC}, \mathrm{CCI}}}{\mathrm{B}}=\frac{\mathrm{M}}{\ln 2} \sum_{\mathrm{k}=0}^{\mathrm{M}-1}\left(\begin{array}{c}\mathrm{M}-1 \\
\mathrm{k}\end{array}\right)(-1)^{\mathrm{k}}\left[\frac{1}{\mathrm{k}+1} \ln \left(\frac{\gamma_{0}+\frac{\Gamma}{\mathrm{k}+1}}{\gamma_{0}}\right)\right]$ \\
\hline & ORA & $\frac{\langle\mathrm{C}\rangle_{\mathrm{ora}}^{\mathrm{SC}, \mathrm{CCI}}}{\mathrm{B}}=\frac{\mathrm{M} \Gamma}{\ln 2} \sum_{\mathrm{k}=0}^{\mathrm{M}-1}\left(\begin{array}{c}\mathrm{M}-1 \\
\mathrm{k}\end{array}\right)(-1)^{\mathrm{k}}\left[\frac{\ln \frac{\mathrm{k}+1}{\Gamma}}{(\mathrm{k}+1)(\mathrm{k}+1-\Gamma)}\right]$ \\
\hline & CIFR & $\frac{\langle\mathrm{C}\rangle_{\mathrm{cifr}}^{\mathrm{SC}, \mathrm{CCI}}}{\mathrm{B}}=\log _{2}\left[1+\frac{1}{\frac{\mathrm{M}}{\Gamma} \sum_{\mathrm{k}=0}^{\mathrm{M}-1}(-1)^{\mathrm{k}}\left[\ln \frac{1}{\mathrm{k}+1}-\left(\ln \frac{\gamma}{(\mathrm{k}+1) \gamma+\Gamma}+1\right)_{\gamma \rightarrow 0}\right]}\right]$ \\
\hline & TIFR & $\frac{\langle\mathrm{C}\rangle_{\text {tif }}^{\mathrm{SC}, \mathrm{CCI}}}{\mathrm{B}}=\log _{2}\left[1+\frac{1}{\frac{\mathrm{M}}{\Gamma} \sum_{\mathrm{k}=0}^{\mathrm{M}-1}\left(\begin{array}{c}\mathrm{M}-1 \\
\mathrm{k}\end{array}\right)(-1)^{\mathrm{k}\left(\frac{-\Gamma}{(\mathrm{k}+1) \gamma_{0}+\Gamma}-\ln \frac{\gamma_{0}}{\gamma_{0}+\frac{\Gamma}{\mathrm{k}+1}}\right)}}\right)\left(\sum_{\mathrm{k}=0}^{\mathrm{M}-1}\left(\begin{array}{c}\mathrm{M}-1 \\
\mathrm{k}\end{array}\right) \frac{\mathrm{M} \Gamma(-1)^{\mathrm{k}}}{(\mathrm{k}+1)^{2}\left(\gamma_{0}+\frac{\Gamma}{\mathrm{k}+1}\right)}\right)$ \\
\hline \multirow{3}{*}{ MRC } & OPRA & $\frac{\langle\mathrm{C}\rangle_{\mathrm{opra}}^{\mathrm{MRC}, \mathrm{CCI}}}{\mathrm{B}}=\frac{\mathrm{M} \Gamma}{\ln 2}\left[\int_{\gamma_{0}}^{\infty} \ln \gamma \frac{\gamma^{\mathrm{M}-1}}{(\Gamma+\gamma)^{\mathrm{M}+1}} \mathrm{~d} \gamma-\frac{\ln \gamma_{0}}{\gamma_{0}}{ }_{2} \mathrm{~F}_{1}\left(\mathrm{M}+1,1 ; 2 ;-\frac{\Gamma}{\gamma_{0}}\right)\right]$ \\
\hline & ORA & $\frac{\langle\mathrm{C}\rangle_{\mathrm{ora}}^{\mathrm{MRC}, \mathrm{CCI}}}{\mathrm{B}}=\frac{1}{\ln 2} \sum_{\mathrm{k}=1}^{\mathrm{M}} \frac{1}{\mathrm{k}}$ \\
\hline & CIFR & $\frac{\langle\mathrm{C}\rangle_{\mathrm{cifr}}^{\mathrm{MRC}, \mathrm{CCI}}}{\mathrm{B}}=\log _{2}(1+(\mathrm{M}-1) \Gamma)$ \\
\hline \multirow{3}{*}{ EGC } & OPRA & $\frac{\langle\mathrm{C}\rangle_{\mathrm{opra}}^{\mathrm{EGC}, \mathrm{CCI}}}{\mathrm{B}}=\frac{\mathrm{M} \Gamma}{v(\mathrm{M}) \ln 2}\left[\int_{\gamma_{0}}^{\infty} \ln \gamma \frac{\gamma^{\mathrm{M}-1}}{\left(\frac{\Gamma}{v(\mathrm{M})}+\gamma\right)^{\mathrm{M}+1}} \mathrm{~d} \gamma-\frac{\ln \gamma_{0}}{\gamma_{0}}{ }_{2} \mathrm{~F}_{1}\left(\mathrm{M}+1,1 ; 2 ;-\frac{\Gamma}{v(\mathrm{M}) \gamma_{0}}\right)\right]$ \\
\hline & ORA & $\frac{\langle\mathrm{C}\rangle_{\mathrm{ora}}^{\mathrm{EGC}, \mathrm{CCI}}}{\mathrm{B}}=\frac{1}{\ln 2} \sum_{\mathrm{k}=1}^{\mathrm{M}} \frac{1}{\mathrm{k}}$ \\
\hline & CIFR & $\frac{\langle\mathrm{C}\rangle_{\mathrm{cifr}}^{\mathrm{EGC}, \mathrm{CCI}}}{\mathrm{B}}=\log _{2}\left(1+\frac{(\mathrm{M}-1) \Gamma}{v(\mathrm{M})}\right)$ \\
\hline
\end{tabular}

\subsection{Expressions for Spectrum Efficiency} when subjected to ACI

From Eq. (1.5-51) of [7], the PDF of the signal to adjacent-channel interference ratio, after the Intermediate Frequency (IF) filter is given in terms of the correlation amplitude, $\lambda$, as

$$
p_{\rho}(\gamma)=\frac{\left(1-\lambda^{2}\right)\left(1+\frac{\gamma}{G}\right)}{G\left[\left(1+\frac{\gamma}{G}\right)^{2}-4 \lambda^{2} \frac{\gamma}{G}\right]^{3 / 2}},
$$

where $\mathrm{G}$ is the power gain of the IF filter for the desired signal relative to the adjacent channel, $\gamma$ is the Signal to Interference Ratio (SIR). The spectrum efficiency of no diversity case and SC diversity scheme for different adaptation policies with ACI was obtained using the PDF (15) in the similar way as explained in section 3.3. which is shown in Table II.

\section{SIMULATION RESULTS}

WiMAX OFDM PHY layer is simulated using MATLAB for the parameters [11] discussed in section 2. Using the $\mathrm{m}$-file for QPSK modulation with 256 subcarriers, average SNR is obtained. These SNR values are substituted in (1) and (3) to obtain SNIR values. SNIR values are substituted in the spectrum efficiency expressions shown in Table 1 and Table 2 to obtain various plots. In the case of CCI, it can be observed that as SNR increases, spectrum efficiency increases and shows remarkable improvement with increase in diversity order. In the case of ACI, spectrum efficiency increases with increase in gain (G). Fig. 2 to Fig. 5 show the spectrum efficiency of the considered system when subjected to CCI. 
Table II: Spectrum efficiency of no diversity case and SC when subjected to ACI [10].

\begin{tabular}{|c|c|c|}
\hline $\begin{array}{l}\text { Diversity } \\
\text { scheme }\end{array}$ & $\begin{array}{l}\text { Adaptation } \\
\text { policies }\end{array}$ & Spectrum efficiency expressions \\
\hline \multirow{4}{*}{ ND } & OPRA & $\begin{array}{l}\frac{\langle\mathrm{C}\rangle_{\mathrm{opra}}^{\mathrm{ACI}, \mathrm{ND}}}{\mathrm{B}}=\frac{\left(1-\lambda^{2}\right)}{\mathrm{G} \ln 2}\left(\frac{\left\{\mathrm{A}\left[\ln \left(\mathrm{A}-2 \lambda^{2} \mathrm{G}+\mathrm{G}+\gamma\right)+\ln \left(\mathrm{A}-2 \lambda^{2} \gamma+\mathrm{G}+\gamma\right)\right]-\ln \gamma(\mathrm{A}-\mathrm{G}+\gamma)\right\}}{2\left(\lambda^{2}-1\right) \frac{\mathrm{A}}{\mathrm{G}}}\right]_{\gamma \rightarrow \gamma_{\mathrm{ma}}} \\
\left.-\frac{\left\{\mathrm{A}_{1}\left[\ln \left(\mathrm{A}_{1}-2 \lambda^{2} \mathrm{G}+\mathrm{G}+\gamma_{0}\right)+\ln \left(\mathrm{A}_{1}-2 \lambda^{2} \gamma_{\mathrm{o}}+\mathrm{G}+\gamma_{\mathrm{O}}\right)\right]-\ln \gamma_{\mathrm{o}}\left(\mathrm{A}_{1}-\mathrm{G}+\gamma_{\mathrm{O}}\right)\right\}}{2\left(\lambda^{2}-1\right) \frac{\mathrm{A}_{1}}{\mathrm{G}}}\right) \text { where } \mathrm{A}=\sqrt{\left(2-4 \lambda^{2}\right) \gamma G+G^{2}+\gamma^{2}}, \\
-\frac{\ln \gamma_{\mathrm{O}}}{2\left(1-\lambda^{2}\right)}\left(G+\frac{G-\gamma_{0}}{\sqrt{1+\frac{\gamma_{0}^{2}}{G^{2}}+\frac{2 \gamma_{0}}{G}\left(1-2 \lambda^{2}\right)}},\right. \\
\mathrm{A}_{1}=\sqrt{\left(2-4 \lambda^{2}\right) \gamma_{0} \mathrm{G}+\mathrm{G}^{2}+\gamma_{0}^{2}} .\end{array}$ \\
\hline & ORA & $\begin{array}{l}\frac{\langle\mathrm{C}\rangle_{\text {ora }}^{\mathrm{ACl}, \mathrm{ND}}}{\mathrm{B}}=\frac{\left(1-\lambda^{2}\right)}{\mathrm{G} \ln 2}\left[\left(\frac{\mathrm{A}\left(\mathrm{B}_{1} \ln \left(\mathrm{A}-2 \lambda^{2} \mathrm{G}+\mathrm{G}+\gamma\right)+(\mathrm{G}+1) \ln \left(\mathrm{AB}_{1}-\left(2 \lambda^{2}-1\right) \mathrm{G}(\gamma-1)+\mathrm{G}^{2}-\gamma\right)\right)-\ln (\gamma+1)\left(\mathrm{AG}+\mathrm{A}+\gamma \mathrm{B}_{1}-\mathrm{B}_{1} \mathrm{G}\right)}{2\left(\lambda^{2}-1\right) \frac{\mathrm{AB}}{\mathrm{G}}}\right)_{\gamma \rightarrow \gamma_{\mathrm{m}}}\right. \\
\left.-\frac{\left(B_{1} G \ln \left(2 G\left(1-\lambda^{2}\right)\right)+(G+1) \ln \left(B_{1} G+G\left(2 \lambda^{2}-1\right)\right)\right.}{2\left(\lambda^{2}-1\right) B_{1}}\right], \text { where } \mathrm{B}_{1}=\sqrt{4 \mathrm{G} \lambda^{2}+\mathrm{G}^{2}-2 \mathrm{G}+1 .}\end{array}$ \\
\hline & CIFR & $\frac{\langle\mathrm{C}\rangle_{\text {cifr }}^{\mathrm{ACI}, \mathrm{ND}}}{\mathrm{B}}=\log _{2}\left(1+\frac{1}{\frac{\left(1-\lambda^{2}\right)}{\mathrm{G}}\left[\frac{\left(1-2 \lambda^{2}\right)^{2}+\lambda^{2}-1}{2 \lambda^{2}\left(1-\lambda^{2}\right)}-\ln \left(\frac{4\left(1-\lambda^{2}\right)}{\mathrm{G}}\right)+\ln \left(\frac{2+\left(\frac{2-4 \lambda^{2}}{\mathrm{G}}\right) \gamma+2 \sqrt{1+\frac{\gamma^{2}}{\mathrm{G}^{2}}+\frac{2 \gamma}{\mathrm{G}}\left(1-2 \lambda^{2}\right)}}{\gamma}\right)_{\gamma \rightarrow 0}\right]}\right]+\frac{1}{2 \mathrm{C}}$ \\
\hline & TIFR & $\begin{array}{l}\frac{\langle C\rangle_{\text {ifr }}^{\mathrm{ACI}, \mathrm{ND}}}{\mathrm{B}}=\log _{2}\left(1+\frac{1}{\frac{\left(1-\lambda^{2}\right)}{\mathrm{G}}\left[\frac{\mathrm{G}}{2\left(1-\lambda^{2}\right)}-\mathrm{G} \ln \left(\frac{4\left(1-\lambda^{2}\right)}{\mathrm{G}}\right)-\frac{\mathrm{G}\left(1-2 \lambda^{2}\right)\left(4 \lambda^{2}-1\right)+\mathrm{G}+2 \lambda^{2} \gamma_{0}}{4 \lambda^{2}\left(1-\lambda^{2}\right)} \sqrt{1+\frac{\gamma_{0}^{2}}{\mathrm{G}^{2}}+\frac{2 \gamma_{0}}{\mathrm{G}}\left(1-2 \lambda^{2}\right)}+\mathrm{G} \ln \left(\frac{\left.2+\left(\frac{2-4 \lambda^{2}}{\mathrm{G}}\right) \gamma_{0}+2 \sqrt{1+\frac{\gamma_{0}^{2}}{\mathrm{G}^{2}}+\frac{2 \gamma_{0}(}{\mathrm{G}}\left(1-2 \lambda^{2}\right)}\right)}{\gamma_{0}}\right)\right.}\right) \\
\times\left(1-\frac{1}{2 \mathrm{G}}\left(\mathrm{G}+\frac{\mathrm{G}-\gamma_{0}}{\sqrt{1+\frac{\gamma_{0}^{2}}{\mathrm{G}^{2}}+\frac{\gamma_{0}}{\mathrm{G}}\left(2-4 \lambda^{2}\right)}}\right)\right)\end{array}$ \\
\hline \multirow[t]{4}{*}{ SC } & OPRA & 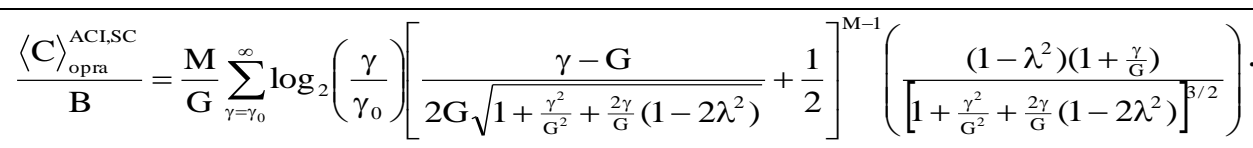 \\
\hline & ORA & $\frac{\langle\mathrm{C}\rangle_{\text {ora }}^{\mathrm{ACI}, \mathrm{SC}}}{\mathrm{B}}=\frac{\mathrm{M}}{\mathrm{G}} \sum_{\gamma=0}^{\infty} \log _{2}(1+\gamma)\left[\frac{\gamma-\mathrm{G}}{2 \mathrm{G} \sqrt{1+\frac{\gamma^{2}}{\mathrm{G}^{2}}+\frac{2 \gamma}{\mathrm{G}}\left(1-2 \lambda^{2}\right)}}+\frac{1}{2}\right]^{\mathrm{M}-1}\left(\frac{\left(1-\lambda^{2}\right)\left(1+\frac{\gamma}{\mathrm{G}}\right)}{\left[1+\frac{\gamma^{2}}{\mathrm{G}^{2}}+\frac{2 \gamma}{\mathrm{G}}\left(1-2 \lambda^{2}\right)\right]^{3 / 2}}\right.$ \\
\hline & CIFR & $\frac{\langle\mathrm{C}\rangle_{\text {cifr }}^{\mathrm{ACISC}}}{\mathrm{R}}=\log _{2} \mid 1+\frac{1}{1}$ \\
\hline & TIFR & $\frac{\langle\mathrm{C}\rangle_{\text {tifr }}^{\mathrm{ACI}, \mathrm{SC}}}{\mathrm{B}}=\log _{2}\left(1+\frac{1}{\frac{\mathrm{M}}{\mathrm{G}} \sum_{\gamma=\gamma_{0}}^{\infty} \frac{1}{\gamma}\left[\frac{\gamma-\mathrm{G}}{2 \mathrm{G} \sqrt{1+\frac{\gamma^{2}}{\mathrm{G}^{2}}+\frac{2 \gamma}{\mathrm{G}}\left(1-2 \lambda^{2}\right)}+\frac{1}{2}}\right]^{\mathrm{M}-1}\left(\frac{\left(1-\lambda^{2}\right)\left(1+\frac{\gamma}{\mathrm{G}}\right)}{\left[1+\frac{\gamma^{2}}{\mathrm{G}^{2}}+\frac{2 \gamma}{\mathrm{G}}\left(1-2 \lambda^{2}\right)\right]^{3 / 2}}\right)}\right) \times\left(1-\left(\frac{\gamma_{0}-\mathrm{G}}{2 \mathrm{G} \sqrt{1+\frac{\gamma_{0}^{2}}{\mathrm{G}^{2}}+\frac{2 \gamma_{0}}{\mathrm{G}}\left(1-2 \lambda^{2}\right)}}+\frac{1}{2}\right)^{\mathrm{M}}\right.$ \\
\hline
\end{tabular}


efficiency when compared to the other policies. The CIFR policy suffers highest capacity penalty relative to the other policies. The spectrum efficiency curve obtained using ORA policy lies in between the curves obtained for the other two policies. OPRA policy yields spectrum efficiency in the range, $3.7309 \mathrm{bps} / \mathrm{Hz}$ to $4.8188 \mathrm{bps} / \mathrm{Hz}$ for $\mathrm{M}=4$, and $3.9123 \mathrm{bps} / \mathrm{Hz}$ to $5.0041 \mathrm{bps} / \mathrm{Hz}$ for $\mathrm{M}=6$. ORA policy yields spectrum efficiency in the range, $2.6375 \mathrm{bps} / \mathrm{Hz}$ to $3.5156 \mathrm{bps} / \mathrm{Hz}$ for $\mathrm{M}=$ 4, and $2.8521 \mathrm{bps} / \mathrm{Hz}$ to $3.761 \mathrm{bps} / \mathrm{Hz}$ for $\mathrm{M}=6$. CIFR policy yields spectrum efficiency in the range, $1.625 \mathrm{bps} / \mathrm{Hz}$ to 2.4459 $\mathrm{bps} / \mathrm{Hz}$ for $\mathrm{M}=4$, and $1.8913 \mathrm{bps} / \mathrm{Hz}$ to $2.762 \mathrm{bps} / \mathrm{Hz}$ for $\mathrm{M}=$ 6. TIFR policy yields spectrum efficiency in the range, 1.729 $\mathrm{bps} / \mathrm{Hz}$ to $2.4744 \mathrm{bps} / \mathrm{Hz}$ for $\mathrm{M}=4$, and $1.9392 \mathrm{bps} / \mathrm{Hz}$ to $2.7683 \mathrm{bps} / \mathrm{Hz}$ for $\mathrm{M}=6$.

Fig. 4 and Fig. 5 show spectrum efficiency curves with respect to average SNR of MRC and EGC diversity schemes under CIFR and ORA policies, respectively, when subjected to CCI for $\mathrm{M}=4$ and $\mathrm{M}=6$. The spectrum efficiency of CIFR policy with MRC diversity scheme lies between $2.3922 \mathrm{bps} / \mathrm{Hz}$ and $3.3319 \mathrm{bps} / \mathrm{Hz}$ for $\mathrm{M}=4$, and for $\mathrm{M}=6$, it is between 3.0148 $\mathrm{bps} / \mathrm{Hz}$ and $4.0104 \mathrm{bps} / \mathrm{Hz}$. The spectrum efficiency of CIFR policy with EGC diversity scheme lies between $2.1377 \mathrm{bps} / \mathrm{Hz}$ and $3.0458 \mathrm{bps} / \mathrm{Hz}$ for $\mathrm{M}=4$, and for $\mathrm{M}=6$, it is between $2.7037 \mathrm{bps} / \mathrm{Hz}$ and $3.6747 \mathrm{bps} / \mathrm{Hz}$. Similarly, for ORA policy with MRC diversity scheme, spectrum efficiency lies between $4.2575 \mathrm{bps} / \mathrm{Hz}$ and $9.0866 \mathrm{bps} / \mathrm{Hz}$ for $\mathrm{M}=4$, and for $\mathrm{M}=6$, it is between $5.0068 \mathrm{bps} / \mathrm{Hz}$ and $10.6858 \mathrm{bps} / \mathrm{Hz}$. For ORA policy with EGC diversity scheme, spectrum efficiency lies between $3.4071 \mathrm{bps} / \mathrm{Hz}$ and $7.2716 \mathrm{bps} / \mathrm{Hz}$ for $\mathrm{M}=4$, and for $\mathrm{M}=6$, it is between $3.8984 \mathrm{bps} / \mathrm{Hz}$ and $8.3203 \mathrm{bps} / \mathrm{Hz}$.

Fig. 6 and Fig. 7 compare spectrum efficiency of OPRA and ORA policy when subjected to ACI with no diversity and SC diversity case. OPRA shows better performance than ORA, and SC diversity scheme serves better than the no diversity case. OPRA policy yields spectrum efficiency in the range of 6.0842 $\mathrm{bps} / \mathrm{Hz}$ to $6.9205 \mathrm{bps} / \mathrm{Hz}$ for no diversity case, and 6.9332 $\mathrm{bps} / \mathrm{Hz}$ to $7.3015 \mathrm{bps} / \mathrm{Hz}$ for SC diversity. ORA policy yields spectrum efficiency in the range $0.0666 \mathrm{bps} / \mathrm{Hz}$ to 0.3749 $\mathrm{bps} / \mathrm{Hz}$ for no diversity case, and $4.1942 \mathrm{bps} / \mathrm{Hz}$ to 4.5198 $\mathrm{bps} / \mathrm{Hz}$ for the SC diversity case. For the SC diversity case, the diversity order is taken as 2. Fig. 8 shows spectrum efficiency of CIFR and TIFR policies when subjected to ACI with no diversity and SC diversity case. The spectrum efficiency of CIFR policy with no diversity case lies between $0.0903 \mathrm{bps} / \mathrm{Hz}$ and $0.3903 \mathrm{bps} / \mathrm{Hz}$, and for SC diversity, it is between 0.0029 $\mathrm{bps} / \mathrm{Hz}$ and $0.012 \mathrm{bps} / \mathrm{Hz}$. The spectrum efficiency of TIFR policy with no diversity case lies between $0.00006 \mathrm{bps} / \mathrm{Hz}$ and $0.0085 \mathrm{bps} / \mathrm{Hz}$, and for SC diversity, it is between $0.018 \mathrm{bps} / \mathrm{Hz}$ and $0.0402 \mathrm{bps} / \mathrm{Hz}$.

\section{CONCLUSIONS}

This paper discusses the effects of CCI and ACI under various adaptation policies and diversity schemes over Rayleigh fading channel in a of WiMAX network with 256 OFDM. The simulation results show that spectrum efficiency is in the range $5 \mathrm{bps} / \mathrm{Hz}$, which is the spectrum efficiency of Fixed WiMAX given by IEEE $802.16 \mathrm{~d}$ standard. Spectrum efficiency improves with an increase in diversity order and an increase in average SIR when the channel is subjected to CCI. For SC diversity case, OPRA policy provides the highest capacity over other adaptation policies. CIFR policy shows the least spectrum efficiency as compared to the other policies. Spectrum efficiency improves with increase in $G$ and $M$, with corresponding increase in average SNR when the channel is subjected to ACI. Also, with SC diversity scheme capacity shows much improvement when compared to the system without diversity. Spectrum efficiency improvement obtained by OPRA policy is higher when compared to the other policies. Thus, OPRA policy with SC diversity is the best suited scheme under ACI.

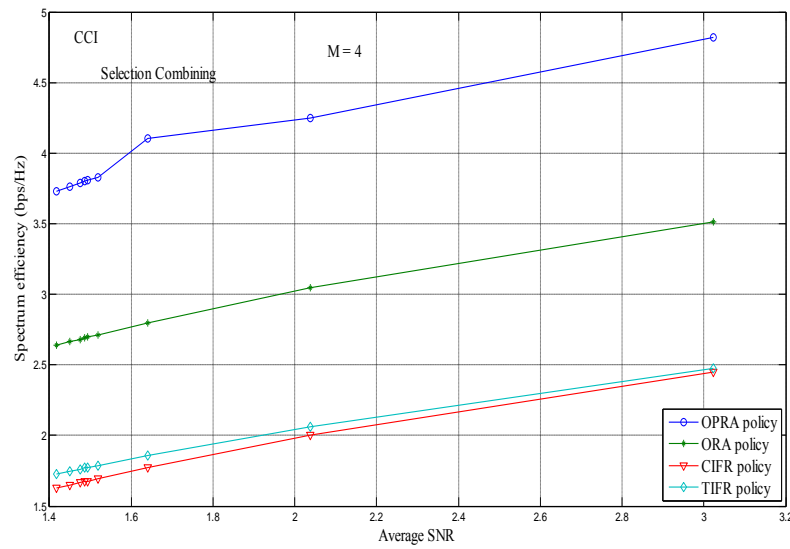

Fig. 2: Spectrum efficiency vs average SNR of OPRA, ORA, CIFR and TIFR policies with SC when subjected to CCI with $\mathrm{M}=\mathbf{4}$.

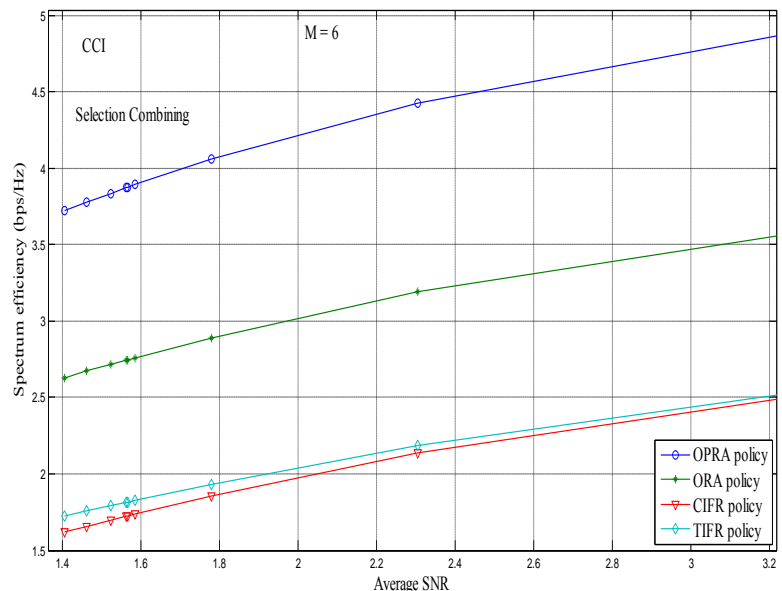

Fig. 3: Spectrum efficiency vs average SNR of OPRA, ORA, CIFR and TIFR policies with SC when subjected to CCI with $\mathbf{M}=\mathbf{6}$.

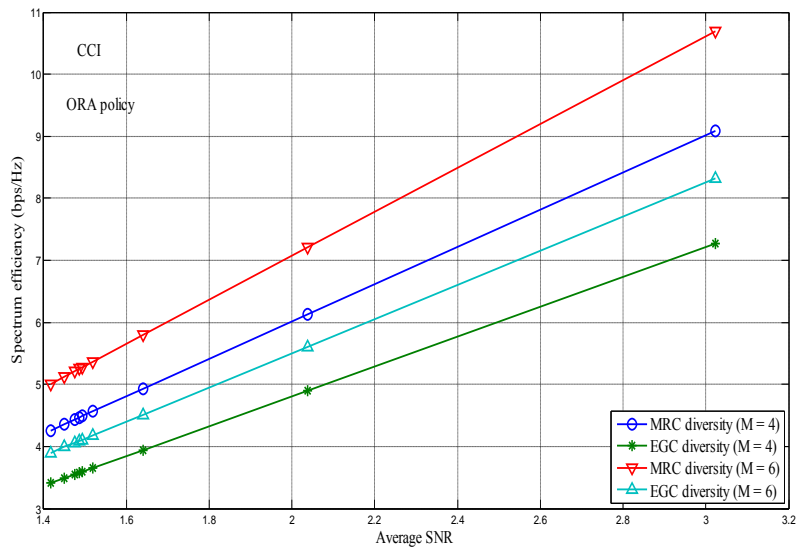

Fig. 4: Spectrum efficiency vs average SNR of ORA policy with MRC and EGC when subjected to $C C I$ with $M=4 \& M$ $=6$. 


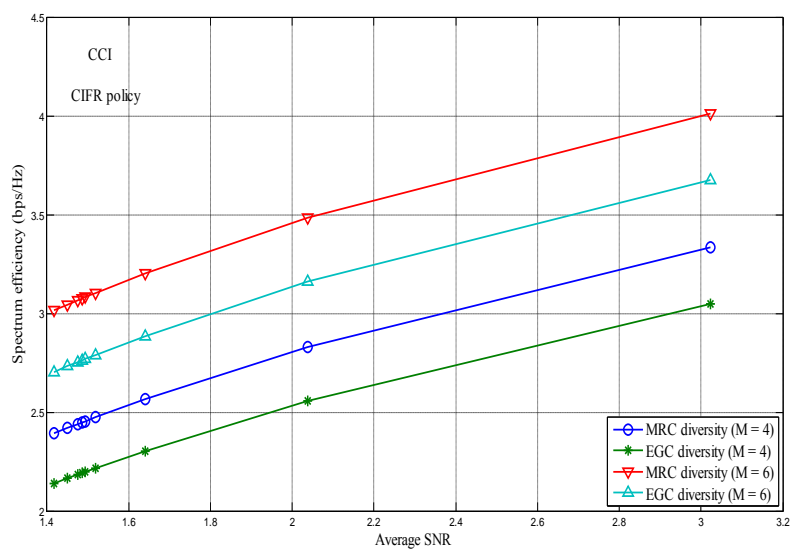

Fig. 5: Spectrum efficiency vs average SNR of CIFR policy with MRC and EGC when subjected to CCI with $M=4 \& M$ $=6$.
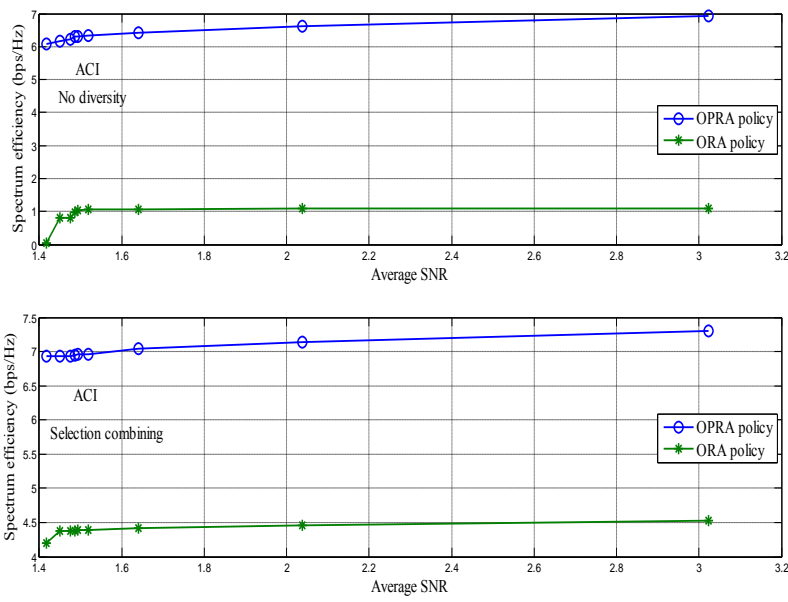

Fig. 6: Spectrum efficiency vs average SNR of OPRA and ORA policies when subjected to ACI.
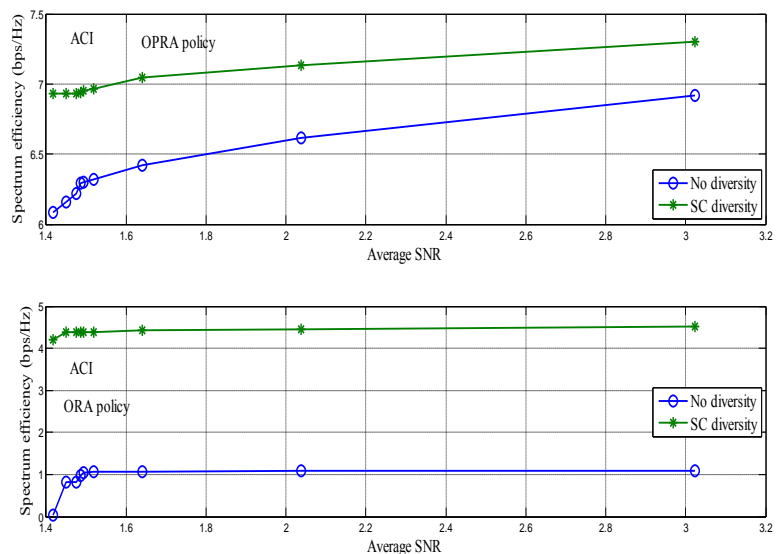

Fig. 7: Spectrum efficiency vs average SNR of OPRA and ORA policies when subjected to ACI.

\section{REFERENCES}

[1] M. Tran, G. Zaggoulos, N. Andrew and A. Doufexi, "Mobile WiMAX: Performance Analysis and Comparison with Experimental Results," Vehicular Technology Conference, VTC 2008, Calgary, BC, DOI. 10.1109/VETECF.2008.438, pp. 1-5, Oct. 2008
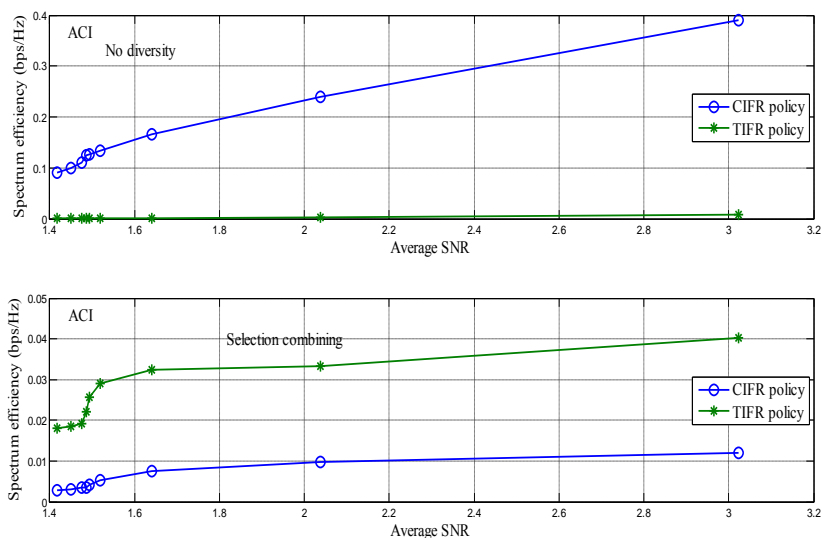

Fig. 8: Spectrum efficiency vs average SNR of CIFR and TIFR policies when subjected to ACI.

[2] J. El-Najjar, B. Jaumard, C. Assi, "Minimizing Interference in WiMax/802.16 based Mesh Networks with Centralized Scheduling," Global Telecommunications Conference, New Orleans, LA, USA, pp.1-6, 30 Nov. -4 Dec. 2008.

[3] Intel White Paper, Wi-Fi and WiMAX Solutions: "Understanding Wi-Fi and WiMAX as Metro-access solutions," Intel corporation, 2004, http://www.rclient.com/PDFs/IntelPaper.pdf.

[4] A. Yarali, B. Mbula, A. Tumula, "WiMAX: A Key to Bridging the Digital Divide", IEEE Proceedings, southeastcon, DOI: 10.1109/SECON.2007.342874, pp. 159 - 164, March 2007.

[5] WiMAX Forum, "Fixed, Nomadic, Portable and Mobile Applications for 802.16-2004 and 802.16e WiMAX Networks," Nov. 2005.

[6] T. Mayer, C. Robertson and T. T. Ha, "Co-Channel Interference Reduction on the Forward Channel of a wideband CDMA cellular system", Military Communications Conference IEEE Proceedings, 1999 , Atlantic City, NJ , USA, vol.2 , pp. 785 - 790.

[7] Jakes W. C., Microwave Mobile Communications, WileyIEEE Press, 2nd edition, May 1994.

[8] V. Bhaskar, "Capacity evaluation for Equal gain diversity schemes over Rayleigh fading channels," International Journal of Electronics and Communications (AEU), vol. 63, pp. 235-240, Jan. 2008.

[9] S. T. Subha, V. Bhaskar, "Spectrum efficiency for Rayleigh fading channels with diversity combining in the presence of Co-channel Interference," IET Communications, Under Review.

[10] S. T. Subha, V. Bhaskar, "Spectrum efficiency for Rayleigh fading channels with diversity combining in the presence of Adjacent channel Interference," IET Communications, Under Review.

[11] J. G. Andrews, A. Ghogh, R. Muhamed, Fundamentals of WiMAX: Understanding broadband Wireless networking, Prentice Hall, 1st edition, Feb. 2007. 